\title{
Investment in Jordan's Health Sector and Future Financial Requirements
}

\author{
Basem M. Hamouri ${ }^{1}$ \\ ${ }^{1}$ Department of Economics and Banking \& Financial Sciences, Faculty of Planning \& Management, Balqa \\ Applied University, Jordan \\ Correspondence: Basem M. Hamouri, Assistant Professor, Department of Economics and Banking \& Financial \\ Sciences, Faculty of Planning \& Management, Balqa Applied University, Salt, Jordan. Tel: 96-277-999-9428. \\ E-mail: basemhamouri@yahoo.com
}

$\begin{array}{ll}\text { Received: March 4, } 2013 & \text { Accepted: April 10, } 2013 \quad \text { Online Published: April 18, } 2013 \\ \text { doi:10.5539/ijef.v5n5p87 } & \text { URL: http://dx.doi.org/10.5539/ijef.v5n5p87 }\end{array}$

\begin{abstract}
The primary objective of this paper is to analyze the impact of demographic changes on future financial requirements and demand for health care services in Jordan. The study anticipates the number of medical personnel and hospital beds required in each governorate until the year 2020 under different sets of population projections. However, the study shows the total expenditure on health services in 1994 and the projected values until the year 2020 using constant and declining fertility rates. Meanwhile, the financial requirements as a percentage of the GDP have been undertaken in this study.

In view of the problem identified, this study recommends that a larger proportion of the GDP and government revenues should be channeled into the health sector. In addition to that, the introduction of highly effective health measures should be accompanied by effective population control programs to sustain the gains from the improvement of health services.
\end{abstract}

Keywords: financing, investment, demographic changes, health sector, budgetary requirements

\section{Introduction}

Health service is defined as the physical, the mental, and the social well being. To insure this, we are supposed to provide, not just financial support, but personnel services such as doctors, nurses, and health technicians and some others services such as environmental, information and research.

Government spending on health from domestic sources is an important indicator of a government's commitment to the health of its people, and is essential for the sustainability of health programs. This study aimed to systematically analyze data sources available for government spending on health sector in Jordan; describe trends in public financing of health; and test the extent to which they were related to changes in gross domestic product (GDP). The global health community has recognized that public spending on health in developing countries is essential for meeting the development goals, reducing poverty, and fighting major diseases (UN, 2001; WHO, 2001). As a result, increasing amounts of international aid have been given to health sectors in developing countries. The assistance for health to the developing countries has risen steadily since 1995 from about US\$8 billion (constant 2007) to nearly \$19 billion in 2006 (Ravishankar, Gubbins, \& Cooley, 2009).

Improvement of government expenditure on health services is very essential for the future financial sustainability of health sector. The domestic government financial support is become necessary if donor funding on health services is diminishing. However, it is very important to treat the health aid as a complementary not as a substitutability for government spending on health services. In addition, citizen people will find themselves enforced to pay from their own living income which will lead them to be below the acceptable standard of living (Van Doorslaer, O’Donnell, \& Rannan-Eliya,2006; Xu, et al., 2003). However, almost all types of expenditures on social services are affected in one way or another by population's changes. Health is one of the salient types that are particularly sensitive to demographic changes of citizens.

Our concern in this study is to see the effects of population growth on budgetary requirements and the health services in Jordan during the years 1994-2020. In this context, different fertility rates are utilized in projecting budgetary requirements and the demand for health personnel and facilities. 


\section{Literature Review}

Reviews of health planning and programs in a world perspective document marked differences in approaches (Maddox, 1982). The welfare of centrally planned and mixed economics, for example, pivots upon centralized national health planning, while in the United States of America, market forces are stressed in the development and allocation of health resources, and approximately $30 \%$ of health care services are financed by the government (Hatcher, 1989).

Alike to the thought of this study, there are two international studies of the health sector which illustrate the impact of demographic changes on government resources required for health care services. One study is an analysis of a developing country, Thailand, while the other is focused upon a developed country, Japan. Both studies have substantially utilized a new population projection technique but based on comparable methodological approaches (Ogawa, 1990; Ogawa, 1989; Ogawa et al., 1989).

Moreover, a number of health sector studies, have estimated the total government medical expenditure without explicitly incorporating the age compositional change of a population. Most of these studies show that the government has played an almost exclusive role in providing health services to the people, except in some places, where the private sector also plays a significant role. For example, the Government of Thailand, from 1979 to 1983 , total government health care expenditures increased from.98 billion to 1.30 billion baht. These expenditures represented $1.17 \%$ of the real GNP in 1979, but grew to $1.43 \%$ in 1983 (Myers et al., 1985; Robinson, 1996; Ichikawa, 1985). Although, the World Health Organization (WHO) states that the increased flows of financial aid to health are important, most public spending on health in developing countries comes from domestic sources. Domestically financed health spending is vital for improving health in the developing countries, (WHO, 2001).

Results from many studies have suggested that a country's gross domestic product (GDP), government size, and external health resources might affect government health financing (Mishra \& Newhouse, 2007; Yontcheva \& Masud, 2005).

Other studies demonstrate that taking into account the factors that contribute to development in governmental financing of health is a crucial issue, mainly the responsibility of ministries of finance. While ministries of health, are devoted to increase the size of health resources. Meanwhile the ministries of finance try to reduce financing of health in the existence of large Development Assistant for Health (DAH) to government (Farag, Nandakumar, Wallack, Gaumer, \& Hodgkin, 2009; Yontcheva \& Masud, 2005; Gottret \& Schieber, 2006).

General Health Expenditure (GHE) is increasing rapidly in the non- developed countries all over the world. DAH is the main answer to the decrease in government expenditure on health services from domestic resources in some developing countries. The improvement in GHE is not simply due to high growth in GDP but is also attributed to increasing General Government Expenditure (GGE) committed to health sector, even as overall size of the government spending in most sectors is diminishing. If this trend keeps on, we assume that the portion of GDP spent by governments on health services will be likely to increase, leading to extended health programs financed throughout government- mediate risk-pooling. Enlarge in the proposed share of government expenditure on health services are expected to take place gradually with time. In the nations where GHE as a proportion of GGE does not raise, additional growth may take long time to catch up with most other nations where increases have take place gradually. A better consideration of issues that might be negatively influencing the share of GGE devoted to health services and discouraging the sustainability of the health sector, such as DAH to government, is required (IHP, 2008).

\section{Methodology}

To understand the effect of different population trends on health service requirements in Jordan, it is necessary to go beyond crude personnel/population ratios and examine the effect of changing population composition on health needs. Two aspects of population composition are likely to have a bearing on health service requirements: the age-sex structure of the population and its regional distribution - specifically large cities, urban, and rural areas.

Different age and sex groups of the population have widely differing probabilities of sickness and recourse to medical attention. Infants and old people are the groups with the highest incidence of sickness and hospitalization. At ages over 50, rates of sickness and hospitalization tend to be high and over 60 they are substantially higher (Ogawa, 1990). Nevertheless, illness among young children constitutes a very significant proportion of the demand for health service because, in a high-fertility population, the number of children, aged five and under, exceeds the total number of people aged 45 and above (see table 1). Therefore, we will see 
whether or not there are big savings in health expenditures which result when the fertility rate falls steadily over a period of more than a decade in Jordan.

In examining the implications of population trends for health needs, the changes in geographic distribution of the population also needs to be taken into account. If some areas are growing faster than others due to more rapid natural increase or immigration, the geographic distribution of health service requirements should be taken into account in health planning.

More important for the strategy of economic health planning is the worldwide tendency towards urbanization. In Jordan, health service ratios are much higher in the cities than in the rest of the country. In most countries, attention is being given to the possibility of narrowing the gap between rural and urban areas with regard to the availability of health services. The goal of simply holding health service ratios constant in the country, as a whole, will mean a decline in health service ratios in urban areas, or in rural areas, or in both.

Table 1. Percentage of age distribution, alternative projections (Jordan 1994*-2020)

\begin{tabular}{llll}
\hline Projections & 1994 & 2014 & 2020 \\
\hline Constant fertility & & & 16.0 \\
$0-4$ & 14.9 & 16.8 & 26.4 \\
$5-14$ & 26.5 & 27.4 & 42.3 \\
$15-44$ & 46.3 & 42.0 & 12.5 \\
$45-64$ & 9.7 & 10.4 & 2.8 \\
$65+$ & 2.6 & 3.4 & \\
Declining fertility & & & 13.5 \\
$0-4$ & 14.9 & 15.0 & 24.4 \\
$5-14$ & 26.5 & 26.7 & 45.3 \\
$15-44$ & 46.3 & 44.5 & 13.8 \\
$45-64$ & 9.7 & 11.0 & 3.1 \\
$65+$ & 2.6 & 2.8 & \\
\hline
\end{tabular}

Source: Projected by the Author.

Note: *Year 1994 is the year of the latest population census.

From the above table we can see that, by virtue of population growth, health costs will raise in Jordan whether or not health service ratios are increased. How likely is it that such cost increases can be sustained? One way to examine this question is to compare the trends in costs with the expected grown of the GDP during the period 1994-2020.

The bulk of the data required for the preceding projections that are necessary for health planning can be summarized as follows:

1) The age distribution of the population of the base year.

2) The abridged life tables for males and females of Jordan's population (see table A.1, and A.2). These contain tables which group the following information:

a. $q(x)$ shows the probabilities of death between ages $\mathrm{x}$ and $x+n$ and computed by using

$$
q(x)=l-(l x+n / l x)
$$

where $l \mathrm{x}$ and $l x+n$ are taken from the $l(x)$.

b. $l(x)$ shows the number of people who survive out of a cohort of 100,000 live births.

c. $d(x)$ shows the number of deaths in each group, calculated by multiplying the number in $q(x)$ by the number in $l(x)$ for each age interval.

d. $l(x)$ indicates the number of persons who lived between age $x$ and $x+n$, which is approximately equal to

$$
L(x)+(n / 2)(l x+n / l x)
$$

e. $S(x)$ is the probability of surviving between two groups of completed years.

f. $T(x)$ is the total number of people in $L(x)$ in the indicated age interval and all subsequent age intervals. In other words, $T(x)=\operatorname{sum} L(x)$.

g. $e(x)$ is the life expectancy, calculated as 


$$
e(x)=T(x) / l(x)
$$

h. $m(x)$ shows the mortality rates for each group. This is the number of death divided by the total population in every age group.

3) Age specific fertility rates (ASFR) for women aged 15 through 49 are required for the analysis.

4) The sex ratio at birth.

By utilizing the preceding data, (in Ralph Sells' model which uses the cohort-component technique for demographic projections), we obtain population projections that show most of the demographic statistics needed for budgetary and personnel requirements of health services. It is also worth mentioning that, to my knowledge, this is the first study which utilizes the population data in the latest population census of 1994 which was released in 1996 to analyze the impact of demographic changes on future financial requirements and demand for health care services in Jordan.

The output of population projections shown in table 2 illustrates that, even if the total fertility rate declines to about ( 4 children per women) in the year 2020, the population will be more than double during the 26-year period. The role of fertility rates can be demonstrated by comparing the total population projected under a declining fertility with that resulting from a continuation of a constant fertility rate.

Table 2. Population size, alternative projections (Jordan) 1994-2020 (in millions)

\begin{tabular}{llll}
\hline Projections & $1994^{*}$ & 2014 & 2020 \\
\hline Constant fertility & 4.139 & 7.677 & 9.817 \\
Declining fertility & 4.139 & 7.293 & 8.896 \\
\hline
\end{tabular}

Source: Projected by the Author.

Note: *From the latest population census.

Nevertheless, the declining fertility rates have effects on the age structure of Jordan's population (see table 3). During the projected period, a decline in fertility will lead to a slow down of the increase in the number of infants and children, but this will have no impact on the number of old people for generations.

Table 3. Percent distribution of population for male female

\begin{tabular}{lllllll}
\hline & $\mathrm{C}$ & $\mathrm{D}$ & $\mathrm{C}$ & $\mathrm{D}$ & $\mathrm{C}$ & $\mathrm{D}$ \\
Age/Year & 1994 & 1994 & 2014 & 2014 & 2020 & 2020 \\
\hline $0-4$ & 14.90 & 14.90 & 17.94 & 15.79 & 16.03 & 13.46 \\
$5-9$ & 13.68 & 13.68 & 15.85 & 14.78 & 13.92 & 12.50 \\
$10-14$ & 12.78 & 12.78 & 13.53 & 13.32 & 12.48 & 11.91 \\
$50-54$ & 2.76 & 2.76 & 3.03 & 3.16 & 3.72 & 4.11 \\
$55-59$ & 2.21 & 2.21 & 2.05 & 2.14 & 2.63 & 2.90 \\
$60-64$ & 1.64 & 1.64 & 1.56 & 1.62 & 1.70 & 1.87 \\
$65-69$ & 1.05 & 1.05 & 1.30 & 1.36 & 1.10 & 1.22 \\
$70-74$ & 0.74 & 0.74 & 0.94 & 0.98 & 0.80 & 0.88 \\
$75-79$ & 0.44 & 0.44 & 0.55 & 0.58 & 0.53 & 0.59 \\
$80-84$ & 0.22 & 0.22 & 0.22 & 0.23 & 0.24 & 0.26 \\
$85-89$ & 0.11 & 0.11 & 0.08 & 0.08 & 0.09 & 0.10 \\
$90-94$ & 0.04 & 0.04 & 0.03 & 0.03 & 0.02 & 0.03 \\
$95-99$ & 0.01 & 0.01 & 0.00 & 0.01 & 0.00 & 0.01 \\
$100+$ & 00.00 & 00.00 & 0.00 & 0.00 & 0.00 & 0.00 \\
Total \% & 100.00 & 100.00 & 106.00 & 106.60 & 100.00 & 100.00 \\
\hline
\end{tabular}

Source: Projected by the Author using (Sell, 1990), computer software packages.

Notes: C: Constant fertility rate. D: Declining fertility rate.

\section{Jordan's Health Sector}

Jordan is characterized by one of the best fashionable health care infrastructure in the region. Similarly, Jordan's health care system is improved dramatically over the last two decades. The health care system in Jordan includes two major sectors: Public and private. The public sector includes the Ministry of Health (MOH) and Royal Medical Services (RMS). In addition, other small public health institutions, such as Jordan University Hospital 
(JUH) and King Abdullah Hospital, are a part of public universities.

Jordan's public health has focused on primary health care in all districts of the country, while leaving tertiary health care mostly to the private sector. Over the past two decades, Jordan's fundamental health indicators have enhanced significantly. The major financer and provider of health services in Jordan is the public sector, which represented by the $\mathrm{MOH}$, complemented by the private sector.

According to the Jordanian Public Health Law No.54, the (MOH) is responsible for all health issues in the country, particularly in (Royal decree, 2002):

- Protecting health through providing preventive and curative services as well as monitoring responsibilities.

- Organizing and supervising health services provided by the public and private sectors.

- Providing health insurance for citizens within available resources.

- Establishing educational and training health institutions managed by the $\mathrm{MOH}$.

Article 4 of the Law illustrates areas of duty for the Ministry including "health promotion and healthy lifestyles, disease control, prevention of nutritional deficiencies, maternal and child health, school health, health of the elderly and prevention and control of no communicable diseases" (Royal decree, 2002). The Law encloses provisions on the practice of medical and health professions, private health care institutions, mental health and drug addiction, communicable diseases, immunization, pharmaceuticals, water and sanitation.

The private sector plays a significant job regarding both the financing and delivery of health services. Many private institutes provide health care insurance for their employees by either self-insuring or the pay for private insurance. Many individuals including those with public health insurance obtain services from private health sector through direct self-payment.

\section{Demand for Health Personnel and Facilities}

Table (4) demonstrates the number of medical personnel and hospital beds required during the years 1994-2020 under two different fertility assumptions and constant service ratios. However, if the fertility rate remains constant, during a 26-year period, almost a 2.4-fold increase in the case of medical personnel and hospital beds will be needed. On the other hand if the fertility rate declines during the same period, the required increase will be about 2.1-fold in medical personnel and hospital beds. It is worth mentioning that, under these circumstances, training requirements, for medical personnel during the coming two decades will be even greater because of the rapid increase in population attrition. However, this depends on both the capacity of Jordan's training institutions to graduate sufficient trained personnel and the cost of training and employing such a large number of required employees.

Column $\mathrm{D}$ in table 4 shows the personnel and hospital beds required under a declining fertility rate. The difference between the numbers under constant and declining fertility rates demonstrates the relative savings in requirements for health personnel during different periods of years. For example, requirements in the year 2020 in the declining fertility projection are about $10 \%$ below those in the constant fertility projection. It is important to mention that, whether health services are kept constant or increased, it will not offset the benefit of fertility reduction.

Table 5, panels A, and B, show the projected health personnel and hospital beds required during the years 2014, and 2020 by governorate under different fertility rates. In this table the geographic distribution includes Amman, Balqa, Zarqa, Irbid, Mafraq, Karak, and the rest of Jordan (ROJ). The data in these panels show the number of medical personnel and hospital beds required in each governorate during the 26-year period.

It should be noted that Amman governorate has more than $60 \%$ of personnel services and hospital beds compared with other governorate in the country. This high percentage refers to the population size in Amman which constitutes $38 \%$ of the population of the whole country, followed by the population size of the governorate of Irbid, Zarqa, Balqa, Mafraq, and Karak respectively (Department of Statistics, 1994). 
Table 4. Projected health personnel and hospital beds

\begin{tabular}{|c|c|c|c|c|c|}
\hline \multirow[t]{2}{*}{ Personnel and facilities } & \multirow[t]{2}{*}{$1994 *$} & \multicolumn{2}{|l|}{2014} & \multicolumn{2}{|l|}{2020} \\
\hline & & $\mathrm{C}$ & $\mathrm{D}$ & $\mathrm{C}$ & $\mathrm{D}$ \\
\hline \multicolumn{6}{|l|}{ Physicians } \\
\hline $\mathrm{MOH}$ & 2217 & 4146 & 3436 & 5301 & 4804 \\
\hline Others & 4379 & 8138 & 7727 & 10406 & 14234 \\
\hline Total & 6596 & 12283 & 11663 & 15707 & 14234 \\
\hline \multicolumn{6}{|l|}{ Dentists } \\
\hline $\mathrm{MOH}$ & 239 & 461 & 437 & 590 & 533 \\
\hline Others & 1359 & 2535 & 2405 & 3241 & 2933 \\
\hline Total & 1598 & 2996 & 2842 & 3831 & 3466 \\
\hline \multicolumn{6}{|l|}{ Pharmacists } \\
\hline $\mathrm{MOH}$ & 170 & 307 & 291 & 393 & 356 \\
\hline Others & 2856 & 5299 & 5030 & 6776 & 6135 \\
\hline Total & 3026 & 2996 & 2842 & 3831 & 3466 \\
\hline \multicolumn{6}{|l|}{ Staff nurses } \\
\hline $\mathrm{MOH}$ & 1342 & 2458 & 2333 & 3143 & 2845 \\
\hline Others & 2411 & 4531 & 4301 & 5793 & 5250 \\
\hline Total & 3753 & 6989 & 6634 & 8936 & 8095 \\
\hline \multicolumn{6}{|l|}{ Midwives } \\
\hline $\mathrm{MOH}$ & 538 & 998 & 948 & 1276 & 1157 \\
\hline Others & 284 & 538 & 510 & 687 & 623 \\
\hline Total & 822 & 1536 & 1458 & 1963 & 1780 \\
\hline \multicolumn{6}{|l|}{ Assistant Nurses } \\
\hline $\mathrm{MOH}$ & 2044 & 3763 & 3572 & 4812 & 4360 \\
\hline Others & 2537 & 4762 & 4520 & 6088 & 5518 \\
\hline Total & 4581 & 8525 & 8092 & 10900 & 9878 \\
\hline \multicolumn{6}{|l|}{ Practical Nurses } \\
\hline $\mathrm{MOH}$ & 2512 & 4685 & 4447 & 5990 & 5430 \\
\hline Others & 700 & 1229 & 1166 & 1427 & 1424 \\
\hline Total & 3212 & 5914 & 5613 & 7417 & 6854 \\
\hline \multicolumn{6}{|l|}{ Hospital Beds } \\
\hline $\mathrm{MOH}$ & 2681 & 4992 & 4738 & 6383 & 5785 \\
\hline Others & 4120 & 7603 & 7217 & 9313 & 8811 \\
\hline Total & 6801 & 12595 & 11955 & 16096 & 14596 \\
\hline
\end{tabular}

Source: Projected by the Author.

Notes: * Ministry of Health, Statistical year book, P. 10, 1994. Others: Mean Royal Medical Services, Jordan University Hospital, and Private Sector.

Table 5. Projected health personnel and hospital beds by governorate and different rates

Panel A: Year (2014) (in thousands)

\begin{tabular}{llllllllllllllllll}
\hline Governorate & $\mathrm{A}$ & \multicolumn{3}{c}{$\mathrm{B}$} & \multicolumn{3}{c}{$\mathrm{P}$} & \multicolumn{3}{c}{$\mathrm{S}$} & \multicolumn{3}{c}{$\mathrm{E}$} & $\mathrm{F}$ & \multicolumn{3}{c}{$\mathrm{G}$} \\
& $\mathrm{C}$ & $\mathrm{D}$ & $\mathrm{C}$ & $\mathrm{D}$ & $\mathrm{C}$ & $\mathrm{D}$ & $\mathrm{C}$ & $\mathrm{D}$ & $\mathrm{C}$ & $\mathrm{D}$ & $\mathrm{C}$ & $\mathrm{D}$ & $\mathrm{C}$ & $\mathrm{D}$ & $\mathrm{C}$ & $\mathrm{D}$ \\
\hline Amman & 4.7 & 4.4 & 1.1 & 1.1 & 2.1 & 2.0 & 2.7 & 2.5 & 0.6 & 0.5 & 3.2 & 3.0 & 2.3 & 2.1 & 4.8 & 4.6 \\
Balqa & 0.8 & 0.8 & 0.2 & 0.2 & 0.4 & 0.4 & 0.5 & 0.5 & 0.1 & 0.1 & 0.6 & 0.5 & 0.4 & 0.4 & 0.8 & 0.8 \\
Zarqa & 1.9 & 1.8 & 0.5 & 0.5 & 0.9 & 0.9 & 1.1 & 1.1 & 0.2 & 0.2 & 1.3 & 1.2 & 0.9 & 0.9 & 1.9 & 1.8 \\
Irbid & 2.2 & 2.1 & 0.5 & 0.5 & 1.0 & 1.0 & 1.3 & 1.3 & 0.3 & 0.3 & 1.6 & 1.5 & 1.1 & 1.0 & 2.3 & 2.2 \\
Mafraq & 0.5 & 0.5 & 0.1 & 0.1 & 0.2 & 0.2 & 0.3 & 0.3 & 0.1 & 0.1 & 0.4 & 0.4 & 0.3 & 0.2 & 0.5 & 0.5 \\
Karak & 0.5 & 0.5 & 0.1 & 0.1 & 0.2 & 0.2 & 0.3 & 0.3 & 0.1 & 0.1 & 0.3 & 0.3 & 0.2 & 0.2 & 0.5 & 0.5 \\
ROJ & 1.6 & 1.5 & 0.4 & 0.4 & 0.7 & 0.7 & 0.9 & 0.9 & 0.2 & 0.2 & 1.1 & 1.1 & 0.8 & 0.7 & 1.7 & 1.6 \\
\hline
\end{tabular}


Panel B: Year (2020)

\begin{tabular}{|c|c|c|c|c|c|c|c|c|c|c|c|c|c|c|c|c|}
\hline \multirow[t]{2}{*}{ Governorate } & \multicolumn{2}{|l|}{$\mathrm{A}$} & \multicolumn{2}{|l|}{ B } & \multicolumn{2}{|l|}{$\mathrm{P}$} & \multicolumn{2}{|l|}{$\mathrm{S}$} & \multicolumn{2}{|l|}{$\mathrm{E}$} & \multicolumn{2}{|l|}{$\mathrm{F}$} & \multicolumn{2}{|l|}{ G } & \multicolumn{2}{|l|}{$\mathrm{H}$} \\
\hline & $\mathrm{C}$ & $\mathrm{D}$ & $\mathrm{C}$ & D & $\mathrm{C}$ & $\mathrm{D}$ & $\mathrm{C}$ & $\mathrm{D}$ & $\mathrm{C}$ & D & $\mathrm{C}$ & $\mathrm{D}$ & $\mathrm{C}$ & $\mathrm{D}$ & $\mathrm{C}$ & $\mathrm{D}$ \\
\hline Amman & 6.0 & 5.4 & 1.5 & 1.3 & 2.7 & 2.5 & 3.4 & 3.1 & 0.8 & 0.7 & 4.2 & 3.8 & 2.8 & 2.6 & 6.1 & 5.6 \\
\hline Balqa & 1.1 & 1.0 & 0.3 & 0.2 & 0.5 & 0.4 & 0.6 & 0.5 & 0.1 & 0.1 & 0.7 & 0.7 & 0.5 & 0.5 & 1.1 & 1.0 \\
\hline Zarqa & 2.4 & 2.2 & 0.6 & 0.5 & 1.1 & 1.0 & 1.4 & 1.2 & 0.3 & 0.3 & 1.7 & 1.5 & 1.1 & 1.0 & 2.5 & 2.2 \\
\hline Irbid & 2.9 & 2.6 & 0.7 & 0.6 & 1.3 & 1.2 & 1.6 & 1.5 & 0.4 & 0.3 & 2.0 & 1.8 & 1.3 & 1.2 & 2.9 & 2.7 \\
\hline Mafraq & 0.7 & 0.6 & 0.2 & 0.1 & 0.3 & 0.3 & 0.4 & 0.3 & 0.1 & 0.1 & 0.5 & 0.4 & 0.3 & 0.3 & 0.7 & 0.6 \\
\hline Karak & 0.6 & 6.0 & 0.2 & 0.1 & 0.3 & 0.3 & 0.4 & 0.3 & 0.1 & 0.1 & 0.4 & 0.4 & 0.3 & 0.3 & 0.7 & 0.6 \\
\hline ROJ & 2.1 & 1.9 & 0.5 & 0.5 & 1.0 & 0.9 & 1.2 & 1.1 & 0.3 & 0.2 & 1.4 & 1.3 & 1.0 & 0.9 & 2.1 & 1.9 \\
\hline
\end{tabular}

Source: Projected by Author.

Notes: A: Physicians, B: Dentists, P: Pharmacists, S: Staff nurses, E: Midwives, F: Assistant nurses, G: Practical nurses, H: Hospital beds, ROJ: Rest of Jordan.

\section{Health Costs}

In this respect, we compare the trends in health costs with the expected growth of the GDP during the time period 1994-2020. Table 6 shows the total expenditure on health services in 1994 and the projected values until year 2020 using constant and declining fertility rates. The data in this table show that the total expenditures on health services under a constant fertility rate will increase from 230 million JD's in 1994 to 426.5 and 545.4 million JD s in the year 2014 and 2020 respectively. Meanwhile this expenditure will increase under a declining fertility rate from 230 million JD's in 1994 to 405.1 and 494.1 million JD's in the years 2014 and 2020 respectively.

If the constant population projection obtains, the total expenditure on health services as a percentage of the GDP, assuming a 5\% growth rate in GDP, will decrease from $8.93 \%$ in the year 1994 to $5.96 \%$ in 2020 ; while under a declining fertility rate projection it will decrease from $8.93 \%$ to $5.39 \%$ during the same period (see table 7). However, if we assume a 7\% growth rate per annum in the GDP, the total expenditure on health services, as a percentage of the GDP under a constant fertility rate will decrease from $8.93 \%$ in the year 1994 to $3.64 \%$ in 2020; while under a declining fertility rate, the total expenditure will decrease from $8.93 \%$ to $3.3 \%$ during the same period (see table 7).

Table 6. Total expenditure on health services, alternative assumptions, 1994-2020 (in millions)

\begin{tabular}{llll}
\hline & 1994 & 2014 & 2020 \\
\hline Total expenditure on health services under a constant fertility rate & $* 230.0$ & 426.5 & 545.4 \\
Total expenditure on health services under a declining fertility rate & 230.0 & 405.1 & 494.1 \\
\hline
\end{tabular}

Source: Projected by Author.

Note: * Ministry of Health, Statistical year book, P. 4, 1994.

The following data show that the share of GDP required under a declining fertility rate (declining population projection) will be less than the share of GDP required under a constant fertility rate. Improving health service ratios in Jordan requires a substantially larger share of the GDP which must be channeled into health services.

Table 7. Total expenditure on health services as a percentage of the GDP at constant prices, alternative assumptions, 1994-2020

\begin{tabular}{lcr}
\hline Assumptions & $1994^{*}$ & 2014 \\
\hline GDP grows at 5\% per annum & & 2020 \\
Constant projection & 8.93 & 6.88 \\
Declining projection & 8.93 & 6.53 \\
GDP grows at 7\% per annum & & 5.39 \\
Constant projection & 8.93 & 4.90 \\
Declining projection & 8.93 & 3.64 \\
\hline
\end{tabular}

Source: projected by the Author.

Note: *GDP values estimated by referring to the Central Bank of Jordan, monthly statistical bulletin, vol.33, no. 4, 1997. 


\section{Conclusions and Recommendations}

The provision of adequate health services is of vital importance to the welfare of the population of Jordan. It is unarguable that increased investment in health services would yield high returns, if returns are measured in ways that reflect the real welfare of the population rather than the more usual measures of output. However, returns from health investment will be much greater, despite the level of expenditures decided if health services are planned to meet health conditions of the country.

The study concluded that general health services and family planning programs should promote and sustain each other, especially if they are set in the context of socioeconomic development. A reduction in fertility rates would not only help directly to ameliorate health problems, but would also make for substantial savings in the cost of providing an adequate level of health care.

The adequacy of health services provided by a given level of expenditure will be greater if the population of Jordan is growing slowly. The following recommendations are proposed to facilitate a better health service in Jordan:

1) Larger proportions of the GDP and government revenues should be channeled into the health sector.

2) A decline in population growth is essential, even if health service ratios in Jordan are to be improved.

3) From a macroeconomic standpoint and for health planning considerations, the introduction of highly effective population control programs to sustain the gains from the improvement of health services.

4) Higher attention should be given to rural areas in the provision of health services.

\section{References}

Central Bank of Jordan. (1997, April). Monthly statistical bulletin. Department of research and studies. Amman.

Department Of Statistics. (1994). The census of population and housing. Amman.

Farag, M., Nandakumar, A. K., Wallack, S. S., Gaumer, G., \& Hodgkin, D. (2009). Does funding from donors displace government spending for health in developing countries. Health Affairs, 28, 1045-1055. http://dx.doi.org/10.1377/hlthaff.28.4.1045

Gottret, P. E., \& Schieber, G. (2006). Health Financing Revisited: A Practitioner's Guide. Washington, DC: World Bank. http://dx.doi.org/10.1596/978-0-8213-6585-4

Hatcher, C. R. (1989, October). The role of government and the private sectors in health care systems. Paper presented at the meeting of the first Japan-United States health care system, Tokyo.

Ichikawa, H. (1985). Future financial requirements for health and pension programmer: Study on the structural change and policies of health economics. In M. Shinohara (Ed.), Tokyo Social Insurance and Welfare Association.

IHP. (2008). High level taskforce on innovative international financing for health systems: Terms of reference and management arrangements. International health partnership. New York.

Institute for Resource Development. (1995). Microcomputer programs for demographic analysis [software]. Columbia, USA.

Maddox, G. (1982). Challenges for health policy and planning, in international perspectives aging: Population and policy challenges. In Robert H. Binstock, Chow Wing-Sun \& James H. Schulz (Eds.), Policy Development Studies (No.7). New York, NY: United Nations Fund for Population Activities.

Mishra, P., \& Newhouse, D. (2007). Health aid and infant mortality. Washington DC: International Monetary Fund.

MOH, \& Department of Statistics. (1990). Jordan Population and Family Health Survey. Amman, Jordan.

MOH. (1994). Statistical Year Book. Jordan.

Myers, C. N., \& Others. (1985). Financing health services and medical care in Thailand. Development Discussion Papers, No. 209, Cambridge, Massachusetts, Harvard Institute for International Development.

Ogawa, \& Others. (1989). Forecasts of health care costs in Thailand. Paper prepared for the National Economic and Social Development Board of the government of Thailand.

Ogawa, N. (1989). Population aging and its impact upon health resource requirements at government familial levels in Japan. Aging and society, 9(4), 383-405. 
Ogawa, N. (1990). Economic factors affecting the health of the elderly in improving the health of older people: A world view. In Robert, L. K., J. Grimley Evans \& David Macfayden (Eds.), A World Health Organization publication. Oxford, United Kingdom, and New York: Oxford University Press.

Ravishankar, N., Gubbins, P., \& Cooley, R. J. (2009). Financing of global health: Tracking development assistance for health from 1990 to 2007. Lancet, 373, 2113-2124. http://dx.doi.org/10.1016/S0140-6736(09)60881-3

Robinson, W. C. (1996). The economic and social impacts of declining fertility in Thailand and the policy options. paper prepared for the National Economic and Social Development Board of the government of Thailand.

Royal Decree. (2002). Public Health Law No.54. Ministry of Health, Jordan.

Sell, R. (1990). Future population, a demographic projection system for microcomputers, [software], W. Brown, Iowa.

UN. (2001). African summit on HIV/AIDS, Tuberculosis and other related infectious diseases: Abuja declaration on HIV/AIDS, tuberculosis, and other infectious diseases. New York, United Nations.

University of Jordan. (1995). Universal health insurance study, submitted to the World Bank, Center for Consultation, Technical Services and Studies, Amman, Jordan.

Van Doorslaer, E., O’Donnell, O., \& Rannan-Eliya, R. P. (2006). Effect of payments for health care on poverty estimates in 11 countries in Asia: An analysis of household survey data. Lancet, 368, 1357-1364. http://dx.doi.org/10.1016/S0140-6736(06)69560-3

WHO. (2001). WHO Commission on macroeconomics and health, macroeconomics and health: Investing in health for economic development, World Health Organization, Geneva.

Xu, K., Evans, D. B., Kawabata, K., Zeramdini, R., Klavus, J., \& Murray, C. J. L. (2003). Household catastrophic health expenditure: A multi-country analysis. Lancet, 362, 111-117. http://dx.doi.org/10.1016/S0140-6736(03)13861-5

Yontcheva, B., \& Masud, N. (2005). Does foreign aid reduce poverty? Empirical evidence from nongovernmental and bilateral aid. International Monetary Fund, Washington DC.

\section{Appendix}

Table A1. Abridged life table for Jordan, males Coale-Demeny west region

\begin{tabular}{lllllllll}
\hline Age & $\mathrm{Q}(\mathrm{x})$ & $\mathrm{D}(\mathrm{x})$ & $\mathrm{M}(\mathrm{x})$ & $\mathrm{l}(\mathrm{x})$ & $\mathrm{L}(\mathrm{x})$ & $\mathrm{S}(\mathrm{x})$ & $\mathrm{T}(\mathrm{x})$ & $\mathrm{E}(\mathrm{x})$ \\
\hline 0 & .03681 & 3681 & 03799 & 100000 & 96900 & .96048 & 6699995 & 67.00 \\
1 & .00815 & 785 & .00205 & 96319 & 383339 & .99255 & 6603095 & 68.55 \\
5 & .00423 & 404 & .00085 & 95534 & 476661 & .99617 & 6219756 & 65.11 \\
10 & .00342 & 326 & .00069 & 95130 & 474837 & .99519 & 5743095 & 60.37 \\
15 & .00620 & 588 & .00124 & 94804 & 472552 & .99257 & 5268259 & 55.57 \\
20 & .00867 & 817 & .00174 & 94216 & 469040 & .99126 & 4795706 & 50.90 \\
25 & .00881 & 823 & .00177 & 93400 & 464940 & .99061 & 4326666 & 46.32 \\
30 & .00997 & 923 & .00200 & 92576 & 460574 & .98865 & 3861727 & 41.71 \\
35 & .01274 & 1168 & .00256 & 91653 & 455347 & .98443 & 3401152 & 37.11 \\
40 & .01844 & 1668 & .00372 & 90486 & 448257 & .97644 & 2945805 & 32.56 \\
45 & .02877 & 2555 & .00584 & 88817 & 437697 & .96323 & 2497549 & 28.12 \\
50 & .04501 & 3883 & .00921 & 86262 & 421602 & .94233 & $2 \mathrm{p} 5852$ & 23.88 \\
55 & .07093 & 5843 & .01471 & 82379 & 397287 & .91075 & 1638250 & 19.89 \\
60 & .10896 & 8340 & .02305 & 76536 & 361830 & .86420 & 1240963 & 16.21 \\
65 & .16591 & 11315 & .03618 & 68196 & 312695 & .79521 & 879133 & 12.89 \\
70 & .25141 & 14301 & .05751 & 56882 & 248657 & .69715 & 566438 & 9.96 \\
75 & .37157 & 15822 & .09127 & 42581 & 173350 & .45450 & 317781 & 7.46 \\
80 & 1.00000 & 26759 & .18527 & 26759 & 144431 & .00000 & 144431 & 5.40 \\
\hline
\end{tabular}

Source: Projected by the Author. 
Table A2. Abridged life table for Jordan, females, Coale-Demeny west region

\begin{tabular}{lllllllll}
\hline Age & $\mathrm{Q}(\mathrm{x})$ & $\mathrm{D}(\mathrm{x})$ & $\mathrm{M}(\mathrm{x})$ & $\mathrm{l}(\mathrm{x})$ & $\mathrm{L}(\mathrm{x})$ & $\mathrm{S}(\mathrm{x})$ & $\mathrm{T}(\mathrm{x})$ & $\mathrm{E}(\mathrm{x})$ \\
\hline 0 & .03481 & 3481 & .03587 & 100000 & 97068 & .96196 & 6900000 & 69.00 \\
1 & .00908 & 877 & .00228 & 96519 & 383911 & .99228 & 6802932 & 70.48 \\
5 & .00395 & 378 & .00079 & 95642 & 477265 & .99648 & 6419021 & 67.12 \\
10 & .00309 & 295 & .00062 & 95264 & 475585 & .99587 & 5941755 & 62.37 \\
15 & .00516 & 490 & .00104 & 94970 & 473622 & .99379 & 5466171 & 57.56 \\
20 & .00727 & 687 & .00146 & 94479 & 470679 & .99200 & 4992549 & 52.84 \\
25 & .00873 & 819 & .00175 & 93792 & 466914 & .99046 & 4521870 & 48.21 \\
30 & .01036 & 963 & .00208 & 92973 & 462457 & .98833 & 4054956 & 43.61 \\
35 & .01300 & 1196 & .00262 & 92010 & 457059 & .98492 & 3592499 & 39.04 \\
40 & .01720 & 1562 & .00347 & 90814 & 450166 & .97918 & 3135439 & 34.53 \\
45 & .02451 & 2187 & .00496 & 89252 & 440794 & .96994 & 2685274 & 30.09 \\
50 & .03576 & 3113 & .00728 & 87065 & 427542 & .95587 & 2244480 & 25.78 \\
55 & .05281 & 4434 & .01085 & 83952 & 408675 & .93299 & 1816938 & 21.64 \\
60 & .08199 & 6520 & .01710 & 79518 & 381290 & .89437 & 1408263 & 17.71 \\
65 & .13138 & 9590 & .02812 & 72998 & 341015 & .83105 & 1026972 & 14.07 \\
70 & .21220 & 13455 & .04748 & 63408 & 283402 & .73532 & 685957 & 10.82 \\
75 & .33130 & 16549 & .07941 & 49953 & 208390 & .48233 & 402556 & 8.06 \\
80 & 1.00000 & 33404 & .17204 & 33404 & 194165 & .00000 & 194165 & 5.81 \\
\hline
\end{tabular}

Source: Projected by the Author. 